\title{
Effect of Cigarette Smoke on Diabetic Skin and Protection with Topical Administration of Pinus halepensis Extract
}

\author{
Varvara Zoumpliou1, Maria Stamatiadi', Clio Vassiliadis', Michail Rallis ${ }^{*}$, \\ Georgios Theodoros Papaioannou', Sotirios Liakos', Alexandros Angelou', \\ Styliani Daskalaki', Maria Kyriazi' ${ }^{1}$, Vasilios Roussis ${ }^{2}$, Constantinos Vagias ${ }^{2 \dagger}$ \\ ${ }^{1}$ Department of Pharmaceutical Technology, Faculty of Pharmacy, National and Kapodistrian University of \\ Athens, Athens, Greece \\ ${ }^{2}$ Department of Pharmacognosy and Chemistry of Natural Products, Faculty of Pharmacy, National and \\ Kapodistrian University of Athens, Athens, Greece \\ Email: ${ }^{*}$ rallis@pharm.uoa.gr
}

Received 19 October 2014; revised 18 November 2014; accepted 2 December 2014

Copyright (C) 2014 by authors and Scientific Research Publishing Inc.

This work is licensed under the Creative Commons Attribution International License (CC BY). http://creativecommons.org/licenses/by/4.0/

(c) (i) Open Access

\begin{abstract}
Compared to normal, diabetic skin is characterized by great sensitivity. Oxidative stress is directly involved, contributing to accelerated skin aging, xerodermia and poor wound healing. In the last 10 years, cigarette smoke (CS) exposure has been associated with several skin and dermatological conditions and is directly related to the oxidative stress affecting the skin. However, limited data exist concerning the effect of CS on diabetic skin. Some of the effects of cigarette smoke exposure on the skin of hairless diabetic mice were hereby studied and the potential skin protection by topical applications of Pinus halepensis bark extract was investigated. Female hairless SKH-2 diabetic mice were exposed for 8 days to tobacco smoke and topical applications were performed twice daily. Biophysical parameters such as transepidermal water loss (TEWL), skin elasticity and erythema were measured. In addition, the oxidative stress was evaluated. The results show that diabetes and CS have a synergistic negative action on skin condition, with the development of xerosis and high ROS levels whilst topical applications of Pinus halepensis bark extract protect efficiently the toxic effect of CS on skin, by decreasing skin dryness, oxidative stress and blood glucose levels.
\end{abstract}

\section{Keywords}

Cigarette Smoke, Skin, Diabetes, Mice, Pinus halepensis Bark Extract

\footnotetext{
${ }^{*}$ Corresponding author.

${ }^{\dagger}$ This author passed away.
}

How to cite this paper: Zoumpliou, V., et al. (2014) Effect of Cigarette Smoke on Diabetic Skin and Protection with Topical Administration of Pinus halepensis Extract. American Journal of Plant Sciences, 5, 3964-3973. 


\section{Introduction}

Tobacco was responsible for more than 100 million deaths worldwide in the 20th Century. The World Health Organization has estimated that, if current trends continue, tobacco could cause a billion deaths in the 21st Century [1]. The pathological effects of cigarette smoke (CS) inhalation have been thoroughly investigated on lungs, the cardiovascular system [2]-[4], the immune system [5] [6] and the reproductive and development systems [7] [8]. However, the cutaneous effects of CS have been comparatively less documented, even though they contribute to the morbidity and reduced quality of life associated with smoking [9].

The skin constitutes the first barrier against environmental aggression and is in direct contact with CS. CS is the result of sidestream and mainstream CS released into ambient air by the actively smoking individuals and contains over 4600 compounds both in gaseous and particulate state that are able to induce oxidative stress to cells. There is considerable evidence showing that reactive oxygen species (ROS) are key contributors to the deleterious effects of CS on skin by increasing oxidant free radicals activity. Tobacco smoke toxins are also known to have a detrimental effect on collagen and elastin integrity and to decrease the microcirculation [9]-[11].

In the last 10 years, CS exposure has been associated with several skin and dermatological conditions, such as premature skin aging, psoriasis, atopic dermatitis, melanoma, poor wound healing, acne, as well as with the yellowing of fingers and nails [9] [10] [12]. However, very limited data exist concerning the cutaneous effect of CS on diabetic skin.

Diabetes mellitus is a metabolic disorder characterized by hyperglycemia and insufficiency of secretion or action of endogenous insulin that can lead to several complications, including dermatological ones. Cutaneous disorders reported include xerosis, acceleration of skin aging, poor wound healing, cutaneous infections and several skin diseases associated with diabetes, such as scleroderma-like changes of the hand, necrobiosis lipoidica, and diabetic dermopathy [13]-[15]. In addition to the high glucose concentration which affects the proliferation and differenciation processes of keratinocytes in diabetes mellitus, increased oxidative stress is known to be involved in the development of these cutaneous complications [16]-[19].

The genus Pinus belongs to the family Pinaceae and comprises about 250 species. The medicinal and aromatic properties of the chemical compounds (e.g., turpentine, resins and essential oil...) of pine make it one of the most popular plants. In the Northern Mediterranean basin, Pinus halepensis is a pioneer and expansionist species that colonizes abandoned agricultural lands characterized by high biodiversity.

Essential oils from Pinus species have been reported to have various therapeutic properties. They are also used as fragrances in cosmetics, flavoring additives for food and beverages, scenting agents in a variety of household products and intermediates in the synthesis of perfume chemicals [20] [21]. Several phytochemical analyses of $P$. halepensis have been published on terpenes [22] [23], turpentine [24] and phenolic compounds [25].

Some previous research suggested that CS was associated with an increased incidence of diabetic skin lesions [26]. The aim of our study was to investigate the effect of CS exposure on the skin of streptozocin (STZ)-induced diabetic hairless mice, as well as the potential protective effect of a topically applied gel of Pinus halepensis bark extract, which is known to be rich in polyphenolic compounds [27].

\section{Materials and Methods}

\subsection{Animals and Experimental Groups}

Hairless female mice type SKH-2 (23 - 32 g) were obtained from the breading stock of the small animal laboratory of the School of Pharmacy of the University of Athens and housed into 4 cages in temperature and humidity controlled chambers ( $12 \mathrm{~h}$ light/12 h dark cycle) with free access to tap water and standard chow diet (Keramaris, Greece). All mice were allowed to acclimate for 20 days prior to the treatment. The housing and treatments of animals were in accordance with our national and institutional guidelines from where specific license was obtained.

\subsection{Treatments}

Diabetes was induced to all mice by a single intraperitoneal injection of streptozocin $(150 \mathrm{mg} / \mathrm{kg})$ solution in sodium citrate buffer (0.1 M, pH 3.5 - 4.5). Blood was collected from the tail for blood glucose determination levels 5 and 8 days after the STZ injection using a glucose monitoring system with electrochemical detector and 
strips (ABBOTT Precision Xtra Plus, USA). The mice were considered as diabetic when the glucose levels were above $180 \mathrm{mg} / \mathrm{dl}$ and in the presence of polydipsia and polyuria symptoms.

The experiment lasts 10 days and was divided into two main phases: phase I before CS exposure (days 0 - 2) and phase II after the start of CS exposure (days 2 - 9). Topical applications were performed during phase I and II.

Mice were divided into the following 3 groups: Seven air-exposed diabetic mice in the first group received a topical application of CMC gel and served as a control. Seven diabetic mice in the second group received a topical application of CMC gel and were exposed to CS. Seven diabetic mice in the third group received a topical treatment of Pinus halepensis bark extract and were exposed to CS.

\subsection{Topical Preparations}

Pinus halepensis bark was collected from Kaisariani Forest which is asuburb close to Athens, in Greece. An extract of it $(12.6 \% \mathrm{w} / \mathrm{w})$ was prepared after 48 hours contact of fine pieces of bark with water solution containing $2 \% \mathrm{v} / \mathrm{v}$ of ethyl alcohol and paper filtration.

The gels were made adding $4 \% \mathrm{w} / \mathrm{w}$ of Carboxymethyl Cellulose (CMC) to the hydro-alcoholic solution containing or not the pine bark extract.

\subsection{Topical Applications}

Mice from groups 1 and 2 were topically treated with the hydro alcoholic gel of Carboxymethyl Cellulose (CMC), twice daily, during 10 days. Mice from group 3 were treated with the hydro alcoholic CMC gel containing the Pinus halepensis bark extract. The topical applications were performed twice daily (morning and evening) with cotton swabs for three days (phase I). Before each application, mice dorsal skin was wiped lightly with cotton to clean the area. After 72 hours (6 applications), CS exposure started for groups 2 and 3 (phase II).

\subsection{CS Exposure}

Whole body exposure of mice to CS was achieved by using a smoking device (Ismatec SA, model CH8152, type MCF, Glattbrugg, Zurich) placed in a custom-made chamber (Figure 1). The device was adjusted to produce a

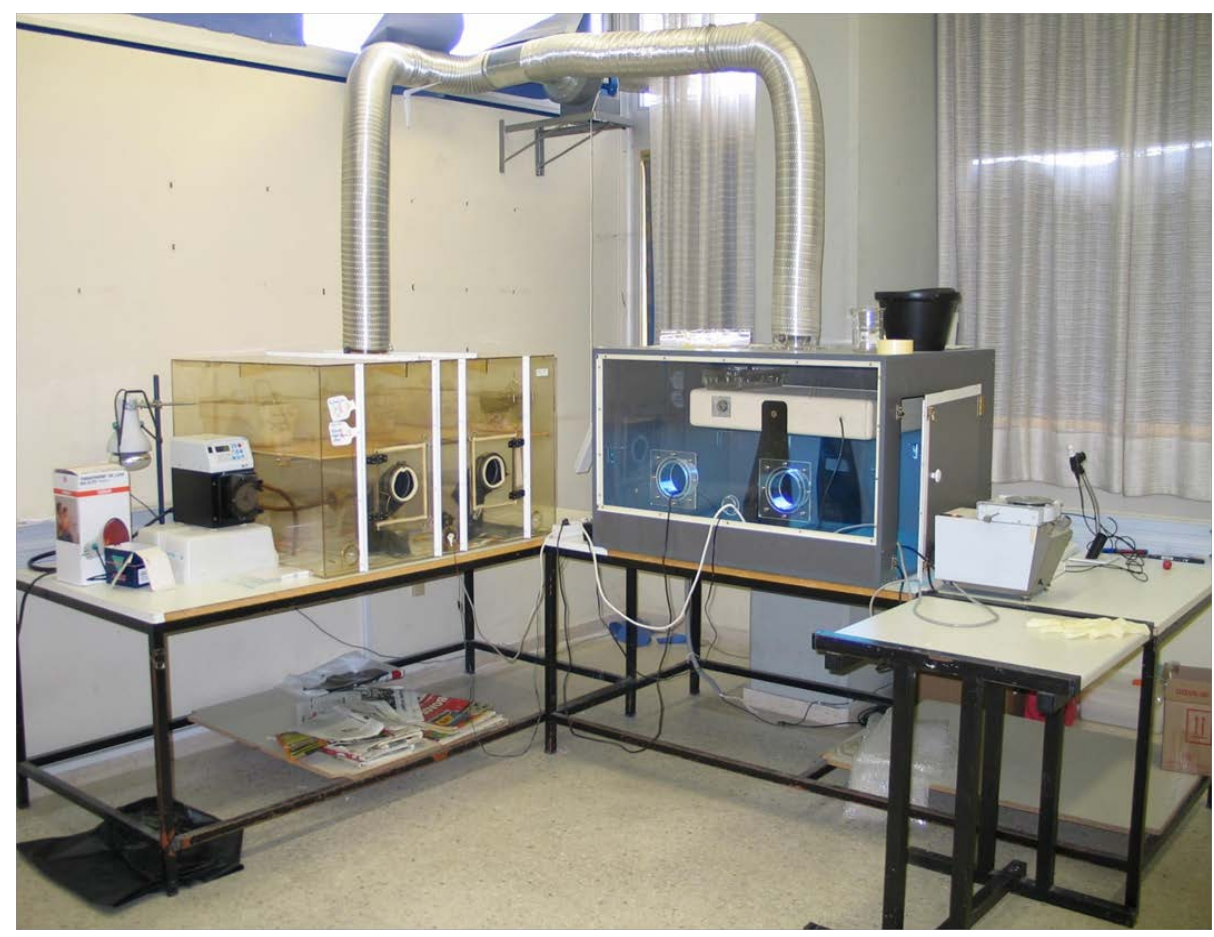

Figure 1. Custom made chamber for CS exposure. 
combination of sidestream (89\%) and mainstream smoke (11\%). CS exposure was generated by burning a cigarette produced in Greece (ASSOS Papastratos; Xanthi, Greece) having a declared content of $10 \mathrm{mg}$ tar, $0.7 \mathrm{mg}$ nicotine and $6 \mathrm{mg}$ CO each. The experiments described above used the standard Federal Trade Commission conditions (puff volume, $35 \mathrm{ml}$; puff duration, $3 \mathrm{~s}$; puff frequency, 1/min). Mice from groups 2 and 3 were exposed to 8 cigarettes for the first day (day 3 of the experiment) and to 4 cigarettes daily for the rest of the experiment. The cigarettes were kept under standardized conditions $\left(4^{\circ} \mathrm{C}\right)$. The animals were maintained in cages within the chamber for continuous exposure and the chamber was ventilated $10 \mathrm{~min}$ twice a day after the topical applications. The mice were exposed to CS 1 hour after the topical applications.

\subsection{Evaluation of Health Conditions}

Measures were taken on day 0 (start of the topical application), on day 5 (the 4th day after the start of exposure to CS) and on day 8 (7th day after the start of CS exposure).The following parameters were measured: 1) blood glucose levels (ABBOTT Precision Xtra Plus, USA), 2) erythema levels by use of a Mexameter MX 18 (Courage and Khazaka, Koln, Germany), 3) transepidermal water loss (TEWL) using a Tewameter TM 210 (Courage and Khazaka, Koln, Germany), 4) skin elasticity by making a skin fold and measuring its restoration time, 5) body weight (Kern Balance 44045 ), 6) overall health of the animals was monitored daily and appropriate pictures were obtained with a digital camera (Sony DSC-W210 Cybershot, 12.1 MPixels, Japan).

\subsection{Oxidative Stress}

After the sacrifice of mice on day 9 (10th day of experiment), oxidative stress was estimated in skin.

ROS levels were measured using a fluorescent probe chloro methyl derivative of dichlorodihydrofluorescein (CM- $\left.\mathrm{H}_{2} \mathrm{DCFDA}\right)$. After treatment and incubation of skin homogenized sample, fluorescence was evaluated using Fluostar Galaxy spectrometer, fluorescence and chemiluminescence meter (BMG, Germany) with excitation filter at $485 \mathrm{~nm}$ and emission at $520 \mathrm{~nm}$.

\subsection{Statistical Analysis}

Results were expressed as means $+/-$ SD. Statistical differences were estimated using analysis of variance (ANOVA) single factor test and considered significant when $\mathrm{p}<0.05$.

\section{Results}

\subsection{Clinical Assessment}

Diabetic smoked mice showed faster and more advanced skin aging signs than diabetic control mice. Xerodermia was observed on day 8 on diabetic smoked mice, whereas in control group, no skin dryness was observable after the same period of time. Among diabetic smoked mice, the group treated with Pinus halepensis bark extract showed less intense aging signs compared to non treated animals. No xerodermia was observed and skin condition was improved compared to the diabetic smoked micenon treated with antioxidant extract (Figure 2).

Macroscopic observation of the skin of diabetic smoked mice showed a yellowish coloration and a decreased vascularisation. It was thinner compared with the skin of diabetic smoked mice treated with the antioxidant extract.

\subsection{Blood Glucose}

A significant decrease in blood glucose levels was observed for the group of diabetic mice exposed to CS and treated with Pinus halepensis extract on day 8 in comparison with the beginning of the experiment $(\mathrm{p}=0.033<$ 0.05). On day 8 , blood glucose levels of this same group of mice were significantly lower compared with diabetic controls $(\mathrm{p}=0.039<0.05)$ whereas this difference was not significant at the beginning of the experiment (Figure 3).

\subsection{Erythema}

Within the group of diabetic smoked mice with antioxidant protection, a significant decrease of skin redness 


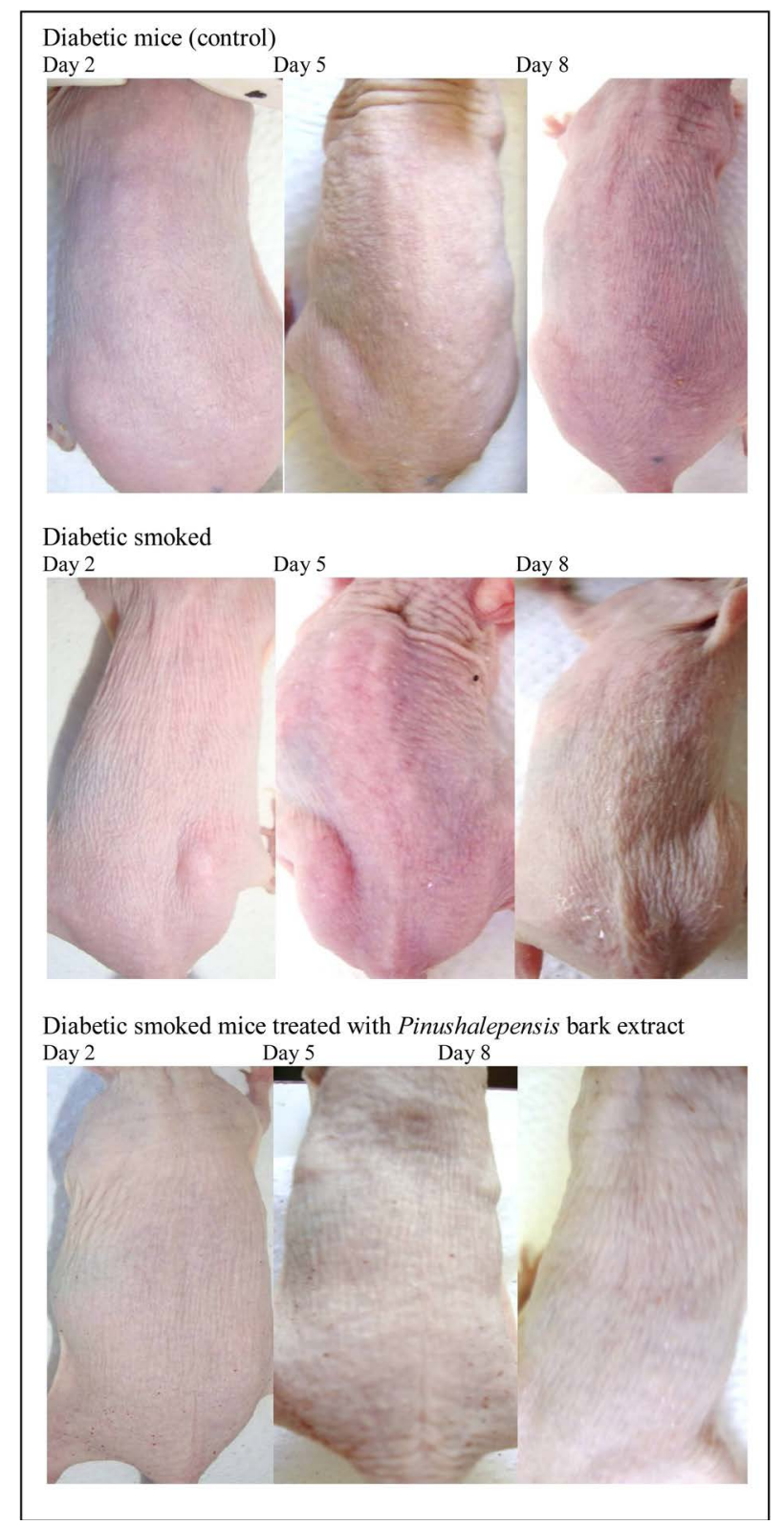

Figure 2. Macrophotographies of diabetic hairless mice during the experiment.

levels was observed between day 5 and day $8(\mathrm{p}=<0.05)$. No important changes were noticed between the other groups of diabetic mice (Figure 4).

\subsection{Transepidermal Water Loss (TEWL)}

No statistic difference was noticed between diabetic smoked mice and diabetic control.

Among diabetic mice exposed to CS, TEWL levels measured on day 8 were notably lower for group treated with the Pinus halepensis bark extract compared with the non treated animals $(\mathrm{p}=0.00043<0.05)$ (Figure 5).

\subsection{Skin Elasticity}

No statistic difference was noticed between diabetic smoked mice and diabetic control mice.

Among diabetic smoked mice, a significant increase of skin elasticity was observed on pine bark treated mice 


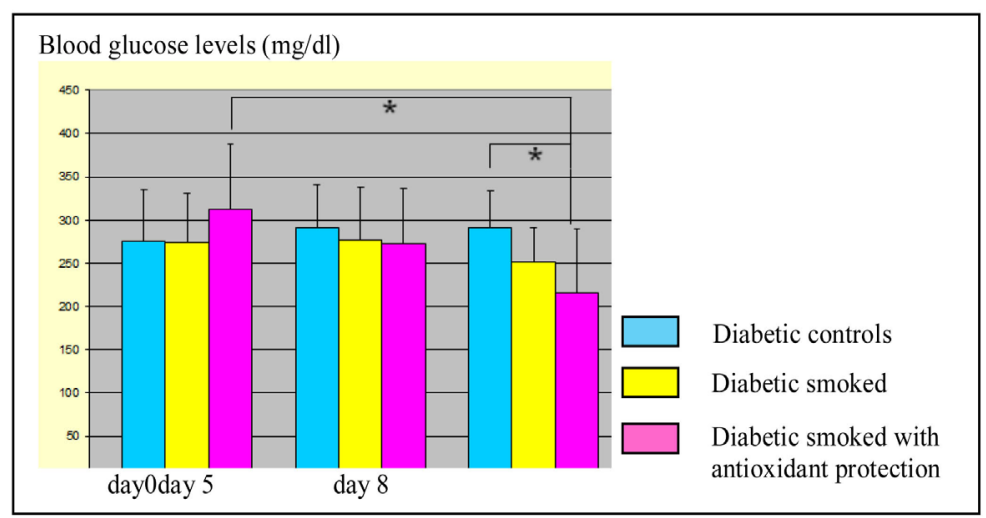

Figure 3. Evolution of blood glucose levels. * Statistical significance $\mathrm{p}<0.05$.

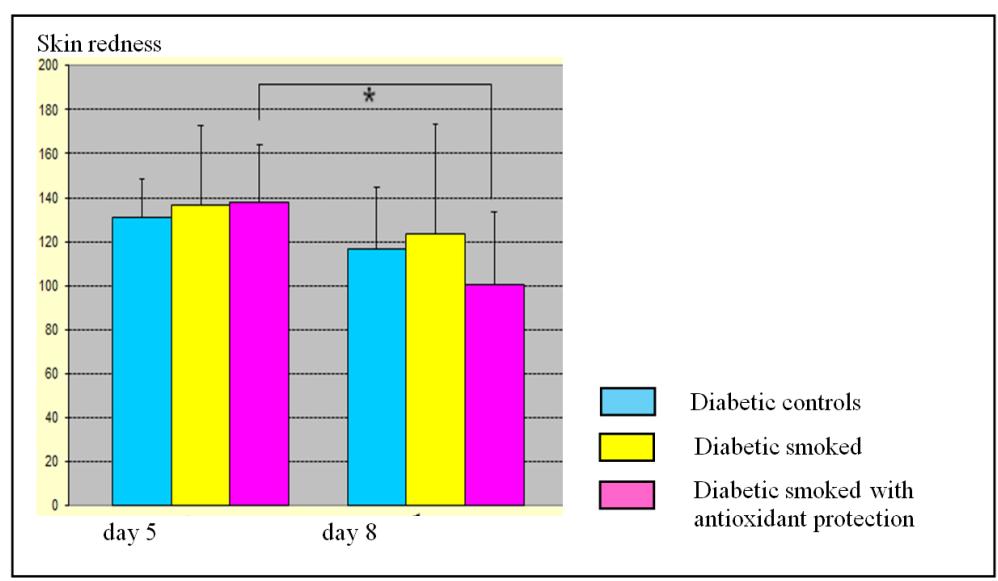

Figure 4. Evolution of skin redness levels. ${ }^{*}$ Statistical significance $\mathrm{p}<0.05$.

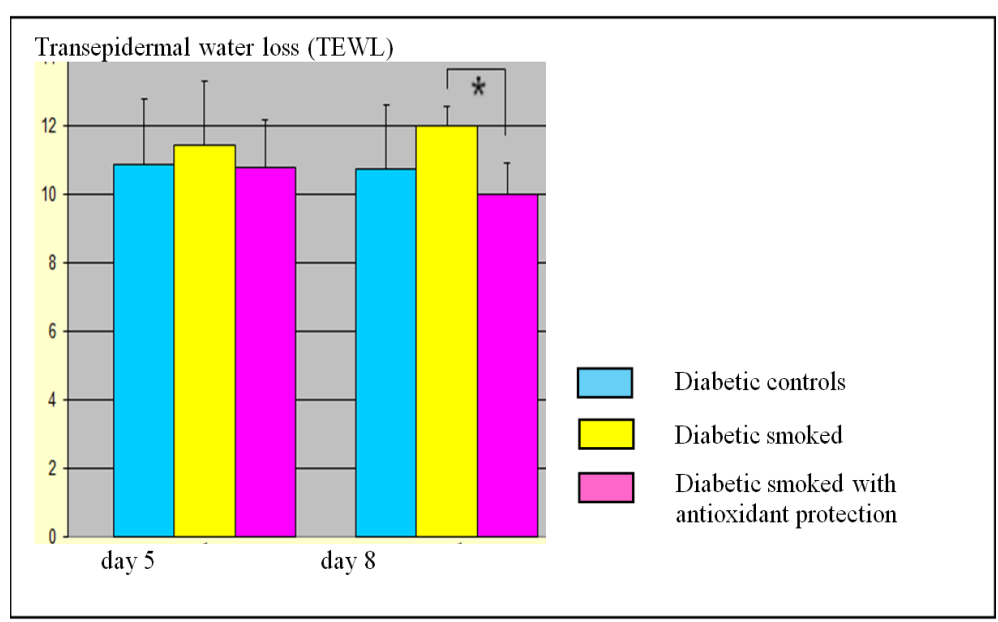

Figure 5. Evolution of transepidermal water loss levels. * Statistical significance $\mathrm{p}<0.05$.

compared with the untreated group (day 5: $\mathrm{p}=0.024<0.05$; day 8: $\mathrm{p}=0.0039<0.05$ ) (Figure 6).

\subsection{Body Weight}

No statistical differences were observed between the mice groups (Figure 7). 


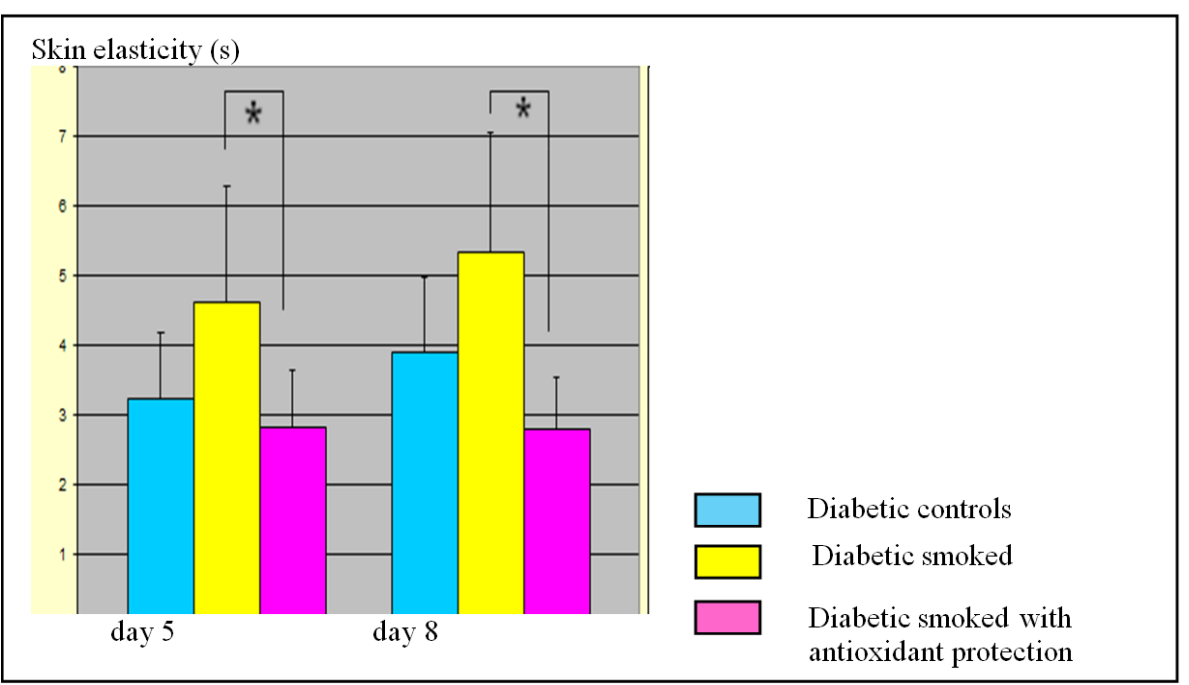

Figure 6. Evolution of skin elasticity. ${ }^{*}$ Statistical significance $\mathrm{p}<0.05$.

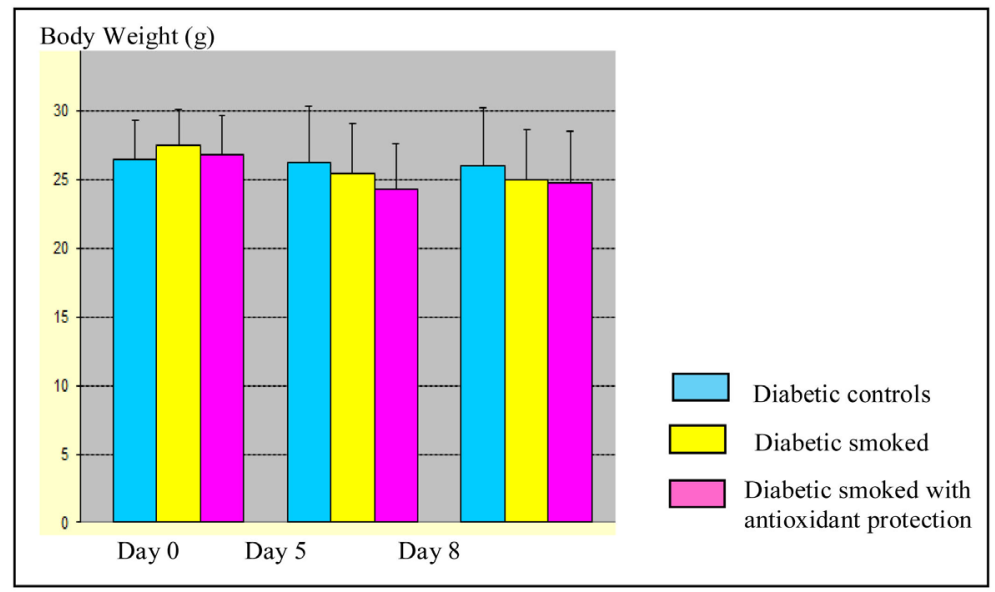

Figure 7. Evolution of body weight. ${ }^{*}$ Statistical significance $\mathrm{p}<0.05$.

\subsection{Oxidative Stress in Skin}

A significant increase in skin oxidative stress of CS exposed mice was observed in comparison with diabetic controls $(\mathrm{p}=0.0045<0.05)$.

Among CS exposed diabetic mice, a significant reduction of skin oxidative stress was noticed for the group treated with pine extract compared with the non-treated one $(\mathrm{p}=0.047<0.05)$ (Figure 8).

\section{Discussion}

The present study results show that exposure of diabetic mice to CS caused xerodermia and shedding (Figure 2). In addition, the skin of these mice took a yellowish coloration, was thinner, had decreased vascularization and elasticity compared to this of the control diabetic mice. These results are in agreement with previous studies which suggest that tobacco smoke alters skin integrity due to impairment of collagen production and increase of tropoelastin and matrix metalloproteinases (MMP) production which leads to elastic fibers and proteoglycans degradation [5].

Diabetic animal skin exposed to CS presented increased TEWL compared to the corresponding control animal (Figure 5). That was also observed by Pavlou et al. [4] on non diabetic long term exposed to CS mice and was attributed to the toxicity of CS towards stratum corneum skin barrier. However, this TEWL increase was observed in a very short period compared with the corresponding of the above mentioned research. It is suggested 


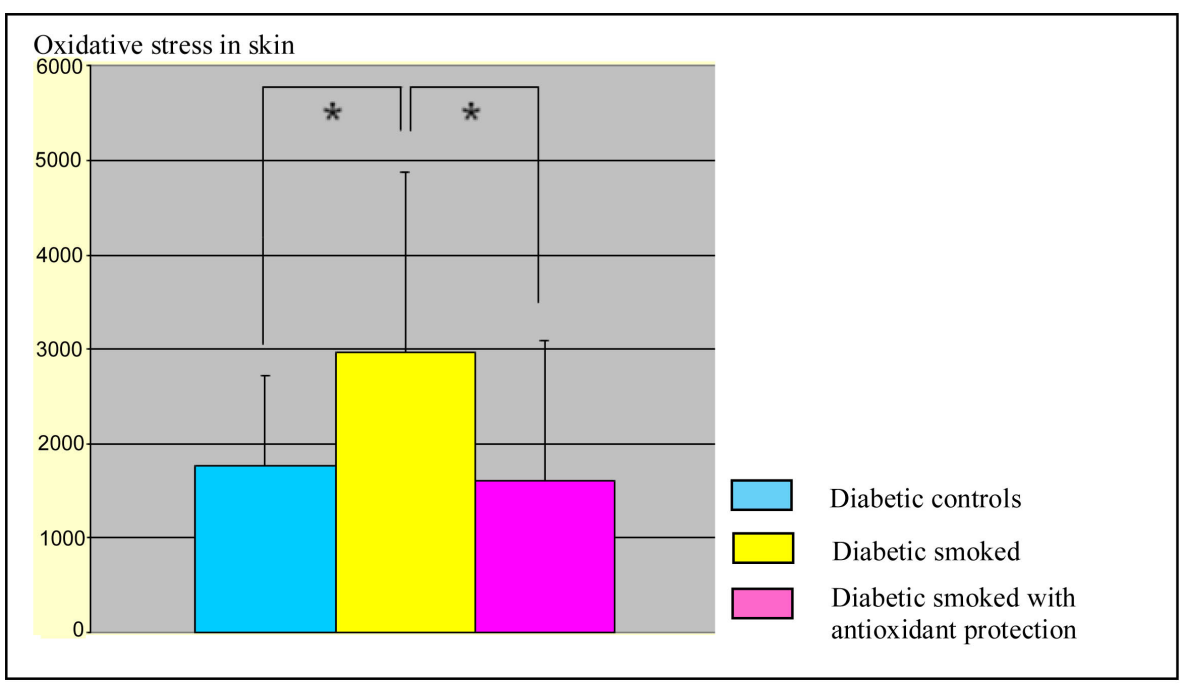

Figure 8. Evolution of oxidative stress levels. ${ }^{*}$ Statistical significance $\mathrm{p}<0.05$.

that this phenomenon should also be attributed to the diabetic profile of animals. Previous studies have shown that diabetes induces many pathphysiological changes in the skin such as reduced mechanical properties (mainly anomalies regarding elastin fibers) and delayed wound healing. Skin dryness has been reported as one of the earliest and most common manifestations of the disease. These cutaneous changes have been reported in both experimental and clinical studies and include a reduced hydration state of the stratum corneum, decreased sebaceous gland activity, impaired desquamation process and decreased triglyceride stratum corneum content [7]-[9] [12]-[14] [28]-[30]. Also, in diabetes, it has been reported that hyperglycemia causes overproduction of reactive oxygen species (ROS) by the mitochondria electron transport chain leading to glucose oxidation and non enzymatic glycation of proteins, which are directly involved in the development of skin complications [6] [12]. Additionally, the measurements of ROS levels in skin revealed a significant increase in the case of diabetic mice exposed to the CS versus control diabetic mice (Figure 8). Taking together all the above mentioned, it can be concluded that the harmful effects on skin are the result of the synergistic action of tobacco smoke and diabetes.

No xerodermia and shedding was noticed and the overall appearance of the skin was improved in the group of treated with Pinus halepensis mice that was thicker and more vascularized compared to nontreated ones (Figure 2). Also, an important and significant reduction of TEWL levels was noticed in this same group of treated mice while TEWL remained merely stable in the two other animal groups (Figure 5). Skin elasticity was also statistically improved in the group of treated mice compared with the non treated group of diabetic mice submitted to tobacco smoke, on days 5 and 8 (Figure 6). The above observations indicate that the local administration of $\mathrm{Pi}$ nus halepensis bark extract helps to maintain a significant degree of hydration in the skin of CS exposed diabetic mice. Another parameter measured was skin erythema that was significantly decreased in the group of treated mice, in contrast to the two other groups of animals in which results were not significant (Figure 4). The improvement of erythema levels, TEWL levels and skin elasticity as well as overall clinical conditions suggest that the topical administration of Pinus halepensis bark extract can effectively protect the skin from CS. This could be due to the potent antioxidant activity of Pinus halepensis bark extract. Previous studies have shown that bark extracts from pinus could protect skin from ROS generated from UV light, chemicals and smoke [31]-[33].

Within the group of diabetic mice exposed to CS and treated with Pinus halepensis bark extract, blood glucose reduction was statistically significant on day 8 compared with day 0 but was also significant compared with the diabetic control group. On the contrary, in the two other groups of animals, blood glucose remained generally stable during the experiment. Thus, it can be concluded that the topically administered antioxidant compounds crossed the disrupted skin barrier and had a hypoglycemia action. So, topical application of Pinus halepensis bark extract could be a candidate to improve glucose levels in diabetes.

\section{Conclusion}

The results show that diabetes and CS have a synergistic negative action on skin condition. There is strong evi- 
dence that Pinus halepensis bark extract could improve oxidative stress induced from environmental factors especially for patients with diabetes. For this reason, some more studies on the synergestic action of UV light and diabetes as well as on the protection of skin by Pinus halepensis bark extract are pending.

\section{Acknowledgements}

Authors would like to thank Abbott pharmaceutical company for providing strips and apparatus for measuring glucose levels, IFET, the National Institute of Pharmaceutical Research and Technology for providing Streptozotocin and Verisfield Company for their financial support.

\section{References}

[1] Cancer Research UK (2014) Healthy Living: Smoking and Cancer. http://www.cancerresearchuk.org/cancer-info/healthyliving/smoking-and-cancer/smoking-and-cancer

[2] Salahundin, S., Prabhakaran, D. and Roy, A. (2012) Pathophysiological Mechanisms of Tobacco-Related CVD. Glob Heart, 7, 113-120. http://dx.doi.org/10.1016/j.gheart.2012.05.003

[3] Ambrose, J.A. and Barua, R.S. (2004) The Pathophysiology of Cigarette Smoking and Cardiovascular Disease: An Update. Journal of the American College of Cardiology, 43, 1731-1737. http://dx.doi.org/10.1016/j.jacc.2003.12.047

[4] Bernhard, D., Moser, C., Backovic, A. and Wick, G. (2007) Cigarette Smoke-An Aging Accelerator. Experimental Gerontology, 42, 160-165. http://dx.doi.org/10.1016/j.exger.2006.09.016

[5] Khanna, A., Guo, M., Mehra, M. and Royal, W. (2013) Inflammation and Oxidative Stress Induced by Cigarette Smoke in Lewis Rat Brains. Journal of Neuroimmunology, 254, 69-75. http://dx.doi.org/10.1016/j.jneuroim.2012.09.006

[6] Zavitz, C., Gaschler, G., Robbins, C., Botehlo, F., Cox, G. and Stampfli, M. (2008) Impact of Cigarette Smoke on T and Bcell Responsiveness. Cellular Immunology, 253, 38-44. http://dx.doi.org/10.1016/j.cellimm.2008.04.012

[7] Radin, R., Hatch, E., Rothman, K., Mikkelsen, E., Soresen, H.T., Riis, A. and Wise, L. (2014) Active and Passive Smoking and Fecundability in Danish Pregnancy Planners. Fertility and Sterility, 102, 183-191. http://dx.doi.org/10.1016/i.fertnstert.2014.03.018

[8] Taymour, M. (2010) Cigarette Smoking and Male Infertility. Journal of Advanced Research, 1, 179-186. http://dx.doi.org/10.1016/j.jare.2010.05.002

[9] Stratton, K., Shetty, P., Wallace, R. and Bondurant, S. (2001) Clearing the Smoke: Assessing the Science Base for Tobacco Harm Reduction. National Academies Press (US), Washington DC, 560-580.

[10] Sticozzi, C., Belmonte, G., Pecorelli, A., Arezzini, B., Gardi, C., Maioli, E., et al. (2012) Cigarette Smoke Affects Keratinocyte SRB1 Expression and Localization via $\mathrm{H}_{2} \mathrm{O}_{2}$ Production and HNE Protein Adducts Formation. PLOS One, 7, e33592. http://dx.doi.org/10.1371/journal.pone.0033592

[11] Pavlou, P., Rallis, M., Deliconstantinos, G., Papaioannou, G. and Grando, S.A. (2009) In Vivo Data on the Influence of Tobacco Smoke an UV Light on Murine Skin. Toxicology and Industrial Health, 25, 231-239. http://dx.doi.org/10.1177/0748233709103209

[12] Morita, A. (2007) Tobacco Smoke Causes Premature Skin Aging. Journal of Dermatological Science, 48, 169-175. http://dx.doi.org/10.1016/j.jdermsci.2007.06.015

[13] Torres, E.B. and Torres-Pradilla, M. (2012) Cutaneous Manifestations in Children with Diabetes Mellitus and Obesity. Actas Dermo-Sifiliográficas, 105, 546-557.

[14] Ahmed, I. and Goldstein, B. (2006) Diabetes Mellitus. Clinics in Dermatology, 24, 237-246. http://dx.doi.org/10.1016/j.clindermatol.2006.04.009

[15] Jones, S. and Hunter, H. (2009) Skin Manifestations of Systemic Disease. Medicine, 37, 277-281. http://dx.doi.org/10.1016/j.mpmed.2009.02.006

[16] Maritim, A.C., Sanders, R.A. and Watkins, J.B. (2003) Diabetes, Oxidative Stress, and Antioxidants: A Review. Journal of Biochemical and Molecular Toxicology, 17, 24-38. http://dx.doi.org/10.1002/jbt.10058

[17] Pavlović, M.D., Milenković, T., Dinić, M., Misović, M., Daković, D., Todorović, S., et al. (2007) The Prevalence of Cutaneous Manifestations in Young Patients with Type 1 Diabetes. Diabetes Care, 30, 1964-1967. http://dx.doi.org/10.2337/dc07-0267

[18] Spravchikov, N., Sizyakov, G., Gartsbein, M., Accili, D., Tennenbaum, T. and Wertheimer, E. (2001) Glucose Effects on Skin Keratinocytes: Implications for Diabetes Skin Complications. Diabetes, 50, 1627-1635. http://dx.doi.org/10.2337/diabetes.50.7.1627 
[19] Piconi, L., Ouagliaro, L. and Ceriello, A. (2003) Oxidative Stress in Diabetes. Clinical Chemistry and Laboratory Medicine, 41, 1144-1149. http://dx.doi.org/10.1515/CCLM.2003.177

[20] Fuentes, J.L., Vernhe, M., Cuetava, E.B., Sanchez-Lamar, A., Santana, J.L. and Llagostera, M. (2006) Tannins from Barks of Pinus caribaea Protect Escherichia coli Cells against DNA Damage Induced by Y-Rays. Fitoterapia, 77, 116-120. http://dx.doi.org/10.1016/j.fitote.2005.11.014

[21] Kozan, E., Kupeli, E. and Yesilda, E. (2006) Evaluation of Some Plants Used in Turkish Folk Medicine against Parasitic Infections for Their in Vivo Anthelmintic Activity. Journal of Ethnopharmacology, 108, 211-216. http://dx.doi.org/10.1016/j.jep.2006.05.003

[22] Kubeczka, K.H. and Schultze, W. (1987) Biology and Chemistry of Conifer Oils. Flavour and Fragrance Journal, 2, 137-148. http://dx.doi.org/10.1002/ffj.2730020402

[23] Asensio, D., Owen, S.M., Llusia, J. and Penũelas, J. (2008) The Distribution of Volatile Isoprenoids in the Soil Horizons around Pinus halepensis Trees. Soil Biology and Biochemistry, 40, 2937-2947. http://dx.doi.org/10.1016/j.soilbio.2008.08.008

[24] Mirov, N.T. and Iloff Jr., P.M. (1955) Composition of Gum Turpentines of Pines. XXIII. A Report on Three Mediterranean Species: Pinus pinea (Cultivated in California), P. halepensis (from Israel) and P. brutia (from Cyprus). Journal of the American Pharmaceutical Association, 44, 186-189. http://dx.doi.org/10.1002/jps.3030440317

[25] Pasqualini, V., Robles, C., Garzino, S., Greff, S., Bousquet-Melou, A. and Bonin, G. (2003) Phenolic Compounds Content in Pinus halepensis Mill. Needles: A Bioindicator of Air Pollution. Chemosphere, 52, 239-248. http://dx.doi.org/10.1016/S0045-6535(03)00268-6

[26] Delbridge, L., Appleberg, M. and Reeve, T.S. (1983) Factors Associated with Development of Foot Lesions in the Diabetic. Surgery, 93, 78-82.

[27] Guri, A., Kefalas, P. and Roussis, V. (2006) Antioxidant Potential of Six Pine Species. Phytotherapy Research, 20, 263-266. http://dx.doi.org/10.1002/ptr.1848

[28] Kim, E., Sohn, S., Lee, M., Jung, J., Kineman, R.D. and Park, S. (2006) Differential Responses of the Growth Hormone Axis in Two Rat Models of Streptozotocin-Induced Insulinopenic Diabetes. Joutrnal of Endocrinology, 188, 263-270. http://dx.doi.org/10.1677/joe.1.06501

[29] Sakai, S., Endo, Y., Ozawa, N., Sugawara, T., Kusaka, A., Sayo, T., et al. (2003) Characteristics of the Epidermis and Stratum Corneum of Hairless Mice with Experimentally Induced Diabetes Mellitus. Journal of Investigative Dermatology, 120, 79-85. http://dx.doi.org/10.1046/j.1523-1747.2003.12006.x

[30] Piérard, G.E., Seité, S., Hermanns-Lê, T., Delvenne, P., Scheen, A. and Piérard-Franchimont, C. (2013) The Skin Landscape in Diabetes Mellitus. Focus on Dermocosmetic Management. Clinical, Cosmetic and Investigational Dermatology, 6, 127-135. http://dx.doi.org/10.2147/CCID.S43141

[31] Kyriazi, M., Yova, D., Rallis, M. and Lima, A. (2006) Cancer Chemopreventive Effects of Pinus maritima Bark Extract on Ultraviolet Radiation and Ultraviolet Radiation-7,12, Dimethylbenz(a)antracene Induced Skin Carcinogenesis of Hairless Mice. Cancer Letters, 237, 234-241. http://dx.doi.org/10.1016/j.canlet.2005.06.005

[32] Jung, H.Y., Shin, J.C., Park, S.M., Kim, N.R., Kwak, W. and Choi, B.H. (2014) Pinus densiflora Extract Protects Human Skin Fibroblasts Against UVB Induced Photoaging by Inhibiting the Expression of MMPs and Increasing Type I Procollagen Expression. Toxicology Reports, 1, 658-666.

[33] Petri, A., Alexandratou, E., Kyriazi, M., Rallis, M., Roussis, V. and Yova, D. (2012) Combination of Fospeg-IPDT and a Natural Antioxidant Compound Prevents Photosensitivity in a Murine Prostate Cancer Tumour Model. Photodiagnosis and Photodynamic Therapy, 9, 100-108. http://dx.doi.org/10.1016/j.pdpdt11.002.2011. 
Scientific Research Publishing (SCIRP) is one of the largest Open Access journal publishers. It is currently publishing more than 200 open access, online, peer-reviewed journals covering a wide range of academic disciplines. SCIRP serves the worldwide academic communities and contributes to the progress and application of science with its publication.

Other selected journals from SCIRP are listed as below. Submit your manuscript to us via either submit@scirp.org or Online Submission Portal.
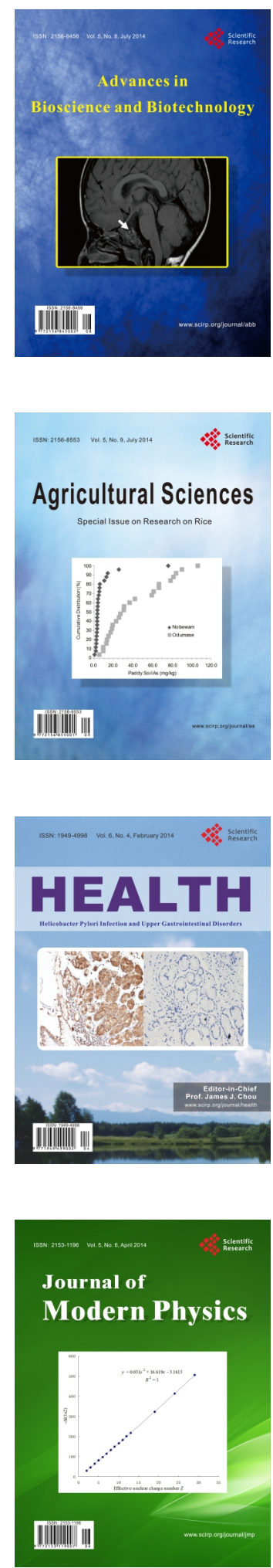
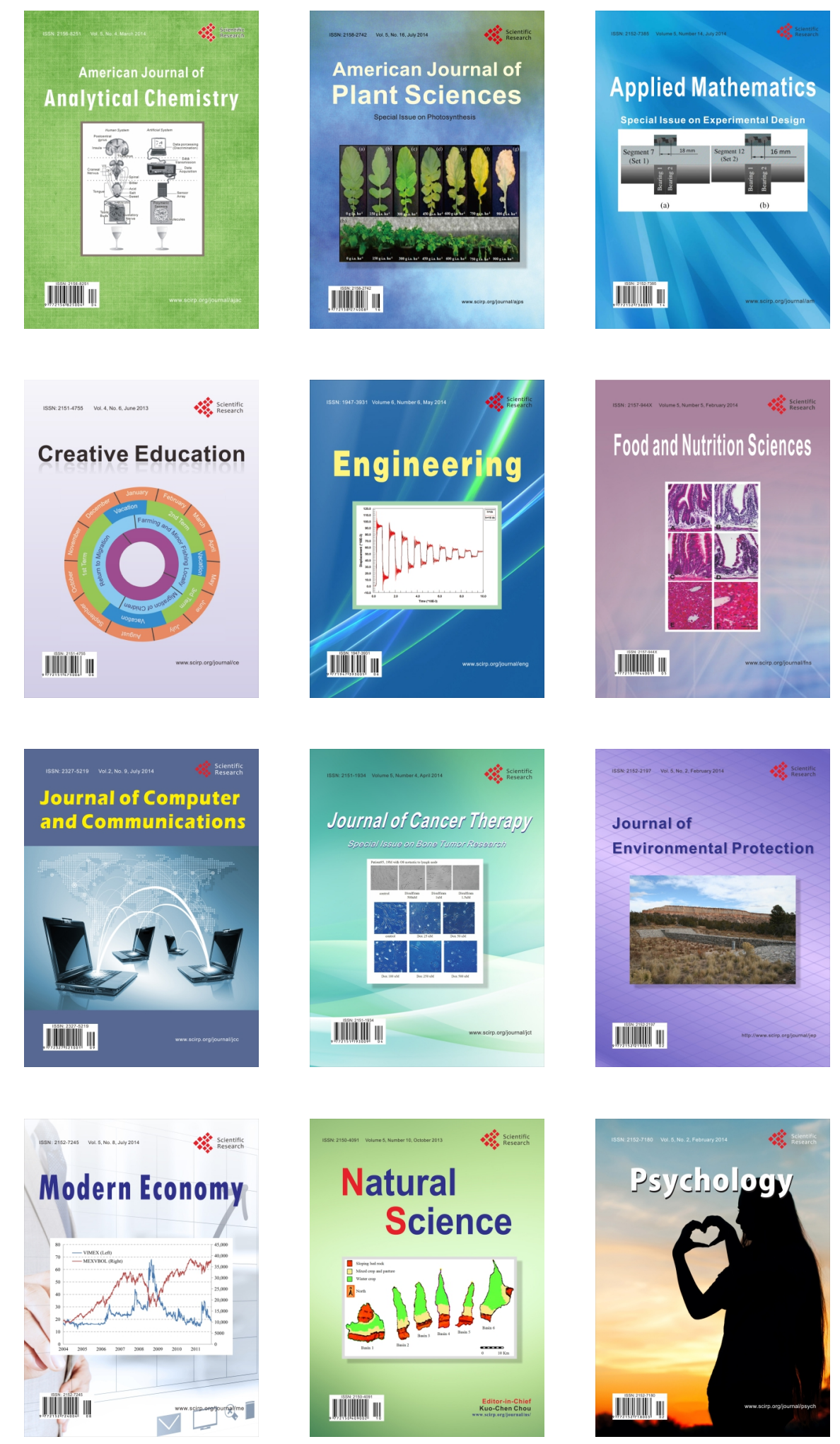